\title{
Science teaching in the UK
}

SIR--M.H. Dodson, in his letter entitled "UK science teaching" (Nature 333, 9; 1988 ) points out that the changes towards balanced science courses have "apparently been approved" by professional bodies with little thought for the implications.

The Institute of Biology has not added its name to a recently published list of supporters of balanced science courses because of its reservations about lack of resources and training, hurriedly prepared syllabuses and possible inadequate preparation of pupils for sixth-form study. The institute has pointed out many times that, unless a course is modular, teachers will be required to teach outside their applications, and until resources are provided for in-service training, standards may drop.

Recruitment to the teaching profession has dropped alarmingly over recent years in all science subjects in the United Kingdom, including biology. This is, in no small measure, due to the tremendous number of changes teachers are expected to cope with, imposed on them by a frantic and didactic government department.

Barbara TOMLins (Education Officer)

Institute of Biology,

20 Queensberry Place,

London SW7 2DZ, UK

SIR-M. H. Dodson (Nature 333, 9; 1988), protesting at the damaging curriculum in British schools, fails to recognize the advantages of 'integrated science' or

\section{Just good friends?}

SIR-Your report on the impact of the review on geology at Imperial College (Nature 327, 489: 1988) refers to a "bitter dispute" between the chairman of the University Grants Committee (UGC) and myself. I assure you that there is none; we are on the best of terms. I see the approach taken by UGC over the past few years as a major advance in tackling the fiendishly difficult problem of how to ensure an equitable distribution of unhappily inadequate resources.

My concern is simply that the application of criteria which are wholly appropriate for the assessment of pure science are likely to give the wrong answer when used with respect to an applied science department. The opposite - judging pure science by an early assessment of its potential utility - is of course equally inappropriate.

Imperial College of Science and

E. A. Ash

Technology,

London SW7 2AZ, UK 'balanced science' for 14-16 year olds. He notes that integrated science is the equivalent, for timetabling purposes, of just two individual subjects and refers to the pressure upon specialist teachers of physics, chemistry and biology to teach outside their own specialities.

But at present fewer than 10 per cent of pupils take three separate sciences in the fourth and fifth years. The introduction of double-certificated science will mean an increase for most children in the amount of science they do at school. On his second point, most schools introducing integrated science divide up the syllabus into its traditional parts, arranging for physics to be taught by a physicist and so on. But physics teachers, and increasingly specialist chemists too, are sufficiently rare in most schools for there to be no chance of their being required to "labour over the microscopy of living cells" as he fears.

Where I do agree with Dobson is that the introduction of such syllabuses, and GCSE in general, has profound consequences for the factual and skills content of A-level subjects. Indeed, the major examination boards are currently producing revised A-level syllabuses. As is widely recognized, British science A levels are very difficult. Many teachers, and the vast majority of students, would welcome changes leading to a broadening of the sixth-form curriculum. Britain desperately needs more science graduates, and does itself no service by making science A levels accessible to only a very small minority of its 16-19-year olds.

Michael J. Reiss

Hills Road Sixth Form College,

Cambridge, CB2 2PE, UK

SIR-As practising science teachers we were surprised at the views expressed by M.H. Dodson (Nature 333, 9; 1988) about the suggested changes in the science curriculum. In particular, Dodson promulgates three serious myths about the present state of science education in Britain.

First, he says that the education that students receive at school is merely an apprenticeship for the real education that they will receive once they reach university. As the vast majority of our students never go to university, this surely represents a major distortion of their curriculum. University entrance requirements have distorted the educational system for too long.

Second, he says that the present standards of science education in Britain are high. By any criterion this is simply not true. We send fewer students on to higher education, particularly in science and engineering, than any of our major industrial competitors. A large proportion of students drop one or more science subjects before the age of 15 . In particular girls drop physical science subjects. The suggested changes in the science curriculum are designed to remedy this appalling state of affairs.

Third, he says the proposed changes suggest balanced science courses not balanced science teachers. While we agree that much in-service training will be needed, we suggest a more appropriate model would be specialist science teachers working together in teams to deliver a more relevant science education in a more relevant way. Incidentally, we both find teaching outside our subject specialities a particularly rewarding experience.

Finally, the only way that we can possibly "broaden our notoriously narrow sixth form curriculum" is to adopt a balanced approach pre-16. If the price that has to be paid for providing a better science education for all our students is that universities have to alter their current teaching practices, then so be it.

Geoff Hayward

Wakefield District College,

Margaret Street,

Wakefield WF1 2DH, UK

North London Science Centre.

Martin Hollins

62-66 Highbury Grove.

London N5 $2 A D, U K$

\section{The data explosion}

SiR-John Maddox (Nature 333, 11; 1988) highlights the thorny issue of data for data's sake versus the search for unifying hypotheses. I believe that the lack of such hypotheses, particularly common in the biological sciences, can be laid in no small measure at the door of journals such as Nature. These publications do not have a section devoted to theoretical papers dealing with the life sciences. Indeed, if an author has the temerity to submit such work for consideration, it is invariably returned with the comment that there are insufficient experimental data. or that it is "not of wide enough interest". Naturally it is much simpler to publish data only, as the guidelines for acceptance are more obvious. On the other hand, it is clearly more difficult to establish such standards for accepting theoretical papers. Nevertheless, publishing such work may serve a more important function in the long run than the reams of data at present filling most space in leading scientific journals. Until journals such as Nature have a regular section devoted to theoretical aspects, particularly in biology, they are playing truant to their responsibility.

Mark A. Gillman

South African Brain Research Institute,

Suite 9, Highlands House,

(NBS Centre),

173 Louis Botha Avenue, Orange Grove,

2192 Johannesburg, South Africa 